\title{
LAS VOCES DESTERRADAS COMO REFUGIO: Trazar la salvaguarda de JOSÉ LUIS PUERTO, Madrid, Calambur, 2012, 144 págs.
}

\section{ASUNCIÓN ESCRIBANO \\ Universidad Pontificia de Salamanca}

Trazar la salvaguarda, el último poe- huellas de marzo», "Cinco motivos clásimario de José Luis Puerto, es un libro cos» y «Dextro: la salvaguarda», Trazar la hermoso. Pero no con la belleza fácil de salvaguarda es un poemario estructurado quien se complace cómodo en el mundo, unitariamente y, sobre todo, es una obra sino con la hermosura que surge de quien, que responde a una misma mirada, la que a pesar de percibir las heridas que van de- convierte en objeto de su interés los rincojando los que ejercen el poder sobre las nes más desapercibidos, pero que permicosas que rozan, es capaz de transformar ten al hombre que recala en ellos el aprenestas en señales de lo vivo y verdadero. dizaje de la salvación personal.

A pesar de su organización interior en Precisamente es en esta última parcuatro partes: «Hilos de tiempo», «Nueve te, «Dextro», donde el escritor relata cómo 
buscaba palabras con «x» para la elaboración de un diccionario, y que fue en el ideológico de Casares donde «me encontré con el término dextro: espacio de terreno alrededor de una iglesia, dentro del cual se gozaba de derecho de asilo». El diccionario apuntaba, por tanto, a un terreno de protección y de salvaguarda, lugar común a todos los libros de Puerto, y centro temático de Trazar la salvaguarda. El libro de Puerto construye, por tanto, desde el título su apuesta poética original. La obra supone de este modo la búsqueda simbólica de un refugio donde protegerse. Como sucedía cuando éramos niños y jugábamos a quién se la quedaba en el pilla-pilla o en el escondite inglés, y siempre estaba como última guarida la «casa». Allí nadie nos rozaba con su daño. Después, con el paso de los años, ya de adultos, ni la casa nos protege. Pero todos volvemos una y otra vez a buscar ese espacio íntimo de la memoria para refugiarnos del daño y su miedo, y ese es el nudo en el que se atan todos los poemas en el libro.

De este modo, Puerto da nombre consciente-como en realidad lo ha hecho siempre en todos sus libros- a esos espacios en los que se siente a salvo, rastreados y sugeridos anteriormente en sus poemarios en términos como «señales», «estelas», «sílabas del mundo» o «moradas»... , aunque ese rastreo en esta obra se ha realizado más honda y conscientemente. Y esos amparos logrados siempre están vinculados al corazón, como bien se señala desde el inicio en las citas de Hölderlin y de Chagall, donde se habla de dar «nombre a lo que se ama»y de que «sólo es mío el país que se encuentra en mi alma». Comparten ambas menciones la alusión a esa doble naturaleza de ciertas cosas de estar fuera del hombre, pero también de haber pasado a formar parte de esa estructura interior que sostiene, como ocurre con los pilares de los edificios, la propia vida.

Los objetos se revelan ante el poeta. Esa es la esencia verdadera de la poesía: comunión. Todo dialoga con quien es capaz de mirarlo todo con temblor. El primer poema es, de esta manera, especialmente significativo y fulgurante. El poeta conversa con el mundo y este le habla de su naturaleza esencial. Pero de todos los mensajes elige dos o tres con los que construye el abanico de sus certezas y de su identidad. Somos aquél diálogo que hemos elegido como guía cierta de nuestra existencia. Lo escuchamos en palabras de Puerto en el poema inicial, titulado «Bayas»: «Dice:/ En el pequeño arbusto/ tan cargado de bayas,/ en el atardecer,/ los jilgueros en una algarabía/ gozosa picotean/ los frutos de un festín/ destinado a los cielos.// Las bayas de esa voz/ son las que me alimentan».

De esta manera, Puerto escoge para hablar de sí mismo y de su poesía -él mismo sobre el papel- el centro de su fe: las bayas de una voz (la del mundo, la de la vida...) que le ofrecen, como si de un jilguero se tratara, sus frutos en el atardecer (¿simbólico, real?), un festín que está destinado a los cielos, pero que hasta los seres más pequeños, los pájaros, pueden disfrutar. Pero, ante todo, lo relevante en este poema no es quién habla, el sujeto, LECTURA Y SIGNO, 9 (2014), pp. 139-144 
sino lo que se dice, el objeto. $Y$ ese contenido del decir es en el que instala el poeta su vida. Las bayas con las que alimenta su trinar son los poemas que constituyen el poemario. Los espacios físicos o mentales que hablan de lo esencial.

Entre ellos, y en primer lugar, la belleza de los excluidos. Una estética que tiene más que ver con la dignidad que con la ornamentación, y que deja su huella por todas partes. Pero, al tiempo, es una belleza que exige sobre todo del hombre un equilibrio en su contemplación suficiente como para poder recalar serenamente en ella. Está en objetos tan diversos como los edificios que han superado la prueba del tiempo, pero donde quedan los rastros de los expulsados. El tiempo aparece así como justo señor, y en las piedras -lo más duro- aparecen talladas las señales de lo más frágil, como ocurre en el abrazo en la ermita de Calatañazor: «Dos cuerpos enlazados/ frente a toda intemperie,/ frente al daño que causan/ la avaricia del tiempo,/ la crueldad de los otros», huella que ha conseguido superar los límites humanos; o en la Seo de Zaragoza, donde perdura la estela de «la belleza que dejaron/ quienes serían expulsados de/ los espacios del reino./ Y permanece aquí/ con todo su fulgor,/ sobrepasando el tiempo/ y hablando de un lugar/ que hoy ya es posible que habitemos todos,/ pues el mundo es morada/ más allá de exclusiones y de dogmas». De igual manera, también los espacios ofrecen a la mirada compasiva del autor una evidente muestra de la exclusión, por lo que le hacen afirmar con tristeza que «Este día proclama el aban- dono/ de la tierra que piso, que transito/ tierras achicharradas/ amarillos del todo calcinados/ pueblos dejados de la mano de/ un Dios vuelto de espaldas».

En segundo lugar están los mediadores de la protección, los rechazados, quienes, por poseer la cualidad de lo vivo, gozan también capacidad de protección, como conciliadores, como enviados, a modo de ángeles (en el sentido etimológico del término). Son lugares sagrados, espacios naturales que hablan al hombre de la Verdad, con mayúsculas. Son ámbitos bienhechores y cifra de lo ajeno al poder económico y a sus profanaciones. Espacios con alma a quienes se les encomienda el cuidado de lo que se ama. De esta manera, al Ara votiva de La Alberca le demanda el poeta la defensa de su propio espacio intocado: «Tú, diosa desplazada,/ Ilúrbeda, patrona/ del lugar, de los bosques,/ protege lo sagrado/ que pervive en mi espacio del origen/ y líbralo de tantas/ profanaciones a que es sometido./ Secreta diosa de un oeste pobre,/ te ofrezco hoy, por todo lo que pido,/ el ara más leal de mis palabras». Otros elementos también se tornan en intercesores, por ejemplo una piña de cedro que, además de hablar de su pertenencia al mundo antiguo, «la necesita el corazón» como hilo de su telar, para lograr la tela más limpia del alma. O un puñado de tierra, que lo es todo, aunque pase desapercibida, por ser la base del hogar, el cuenco para las semillas, o el amparo futuro para el cuerpo, «don que al misterio me liga»...

Por el poemario transitan', de este modo, lugares, personas y experiencias 
salvadoras a las que se les pide ayuda y que, aunque pasen inadvertidas, nos sostienen y por ello les debemos gratitud: «Otoño/ te pido protección/ esta mañana clara de diciembre,/ envuélveme en la luz/ y hazme arder en tus oros».

Con frecuencia son elementos pequeños o frágiles, que recuerdan al hombre su naturaleza fundamental, por ejemplo, las alas de la mariposa que «es la belleza humilde/ que me regala el día», y que es signo y posibilidad de un vuelo vital más alto. Son las grafías pequeñas que hablan de otras huellas más grandes y poderosas, $\mathrm{y}$ a las que el poeta saber mirar de manera desacostumbrada, traduciéndolas al idioma de los afectos. Muchos de estos signos se vinculan a la infancia como refugio y el escritor las muestra como paradigma de los códigos salvadores de entonces: «Qué llevas en tu vientre,/ pequeño pez de plata» (...), «Dame tu protección, / dime cuál es la frase/ sagrada que contienen tus adentros» (...), «Transpórtame hasta el centro de mi origen»... Son los espacios tocados por la gracia, los ámbitos del corazón, portadores de mensajes de amparo: «Pétalos delicados/ que creais un espacio circular/ defendido de todos los peligros». Ejemplos de lo pequeño desapercibido, solo descubierto cuando nos visita su fulgor, como ocurre en el poema titulado «Candelina», en el que lo que asciende lo hace por la ligereza de su ser: «Pequeño insecto moteado/ que haces de lo minúsculo el emblema/ Más hermoso y más libre».

Entre esos ámbitos redentores, llama la atención por su intensa presencia emocional el mundo de lo femenino, lugar de sanación de todas las heridas. Son los diferentes rostros de la mujer los que preservan la vida del escritor: la madre, la esposa, la hija..., el hogar por excelencia, espacio de plenitud, morada y amparo: «Extiendo bien mi mano,/ la coloco en tu vientre/ como esfera lograda de mi mundo,/ lugar de las semillas,/ calidez protectora,/ espacio femenino que nos salva»... Y junto al salvador espacio femenino, también sostienen la vida propia la experiencia redentora de los más ancianos, que portan la mirada llena del amor y la dignidad de quien va por delante en lo vivido, y cuyo vocablo transporta la claridad con su melodía antigua, «La voz de los ancianos/ la de la potestad/ la que conoce el mundo y lo pronuncia/ la voz de la advertencia y el aviso/ también la de la súplica/ la de la profecía». En la poesía de José Luis Puerto, toda la vida posee un temblor sagrado y todos los objetos naturales tienen esa capacidad de ser intercesores de la bondad.

El tercer ámbito temático es la palabra y su supuesto rostro antagónico, representado por el silencio, cuya cadencia recóndita es reivindicada por el escritor. Puerto considera así que las voces de la derrota se hacen escuchar siempre y, aunque su momento se dilate, su presencia se acaba imponiendo, a pesar de la presión de los poderosos por acallarlas. «Proclama tu silencio/ la melodía de la dignidad./ Se oyen las voces de los derrotados,/ sus herederos hablan,/ los fusilados del amanecer./ Cunetas y cunetas/ al olvido entregadas/ por la barbarie de los venceLECTURA Y SIGNO, 9 (2014), pp. 139-144 
dores./ Hay que desenterrar/ la melodía hermosa/ de los asesinados/ que callen las descargas,/ que florezca la lengua/ reconciliada y fraternal de todos./ Habla tú melodía/ por tanto tiempo sepultada,/ la del honrado pueblo soberano».

Con el único lenguaje posible, el de la paradoja, ensayado de manera vigorosa desde antiguo en nuestro idioma por poetas y místicos, José Luis Puerto se refiere a la doble identidad de las palabras. Esa doble naturaleza de los vocablos cuando son íntimos que obliga a que para nombrar con contundencia se tenga necesariamente que rozar los territorios del mutismo («Calla/ y di desde el silencio»; «Pájaro y hombre,/ canto y silencio,/ todo procla$\mathrm{ma} /$ la hermosa melodía/ que a todos nos abraza»). Términos que, por otro lado, cuanto más auténticos son, más se imprimen en el alma de quien los pronuncia.

La palabra es, por tanto, un don sagrado y presenta las cualidades que la hacen poseer esta peculiaridad. La palabra puede mostrar todos los gestos posibles de la redención: callada, cantada, rezada, entregada, esperada, buscada, anhelada, ofrecida, sentida... Es «melodía que nos salva» y que nos lleva hasta la plenitud en su afán cabalístico: «¿Y cuáles son las sílabas/ que den con el prodigio que esperamos?», escribe en esta dirección Puerto. Se busca y halla, por otro lado, en el vértice entre lo que percibimos y lo que hay.

Frente a la palabra del poder, vacía, «el gastar palabras para poco», en la que se violenta su sentido sacral, el poema se sitúa en el cruce íntimo entre el mirar y el ser, «el silencio secreto del que calla / el vuelo de los pájaros». De ahí que en la línea de J. R. Jiménez que pedía a la inteligencia su exactitud, Puerto pide al alma que abrace en ella los senderos del corazón: «Canta/ pronuncia la palabra/ exacta y clara/ de la mañana/ acaricia las cosas/ abrázalas». La caricia, por tanto, frente al pensamiento. La apuesta por la sensibilidad en lugar de la razón... Por ello, esta actitud respetuosa, casi sacral, frente al nombrar exige unas dosis intensas de sosiego y lentitud al nombrar para permitir el paladeo nominal que hace degustar al vida, como un mantra en el que el escritor consigue «calmar la sed/ y apaciguarnos». Es esta una forma de humildad escogida de quien decide permanecer fuera de los focos, y con ello conseguir hallar las «señales de lo que está escondido».

Finalmente, el cuarto ámbito está constituido por todos aquellos poemas que apuntan a la identidad del hombre verdadero, el hombre que lleva su dignidad como un faro que ilumina. Aquí se encuadrarían una serie de poemas estructurados de manera original en torno a un único componente oracional, que se reitera en variantes anafóricas, con la intención de focalizar y resaltar su importancia: «El que camina con su dignidad/ el que va por la calle a cuerpo limpio/ el sobrio, el que se entrega/ el que no pide nada y va en silencio»... Como se puede comprobar, en estos poemas el escritor decide prescindir del verbo principal, puesto que lo que le interesa es el resalte, la función deíctica, señaladora -tan bien manejada por los niños en sus primeros años- manifestada también en la sintaxis, 
e incidir en la relevancia de esa forma de ser, convertida a través de estos textos en paradigma de autenticidad: «El amigo del sueño,/ el amigo de las constelaciones,/ el buscador nocturno de luciérnagas,/ el amigo del vuelo de los pájaros,/ del canto de los pájaros,/ el que contempla desde abajo el mundo/ (...) Ese».

Se construye, de este modo, a través de la reiteración acumulativa de propiedades al hombre auténtico, el digno de ser imitado por los demás. Por ello no extraña que Puerto recomiende a sus lectores «estate bien cerca/ De todo lo que importa», puesto que lo verdadero se encuentra ya en el propio proceso del buscar y en sus señales lingüísticas. Entre estas, y de manera significativa, el imperativo adquiere en los poemas las propiedades de la advertencia, de la invitación suave pero contundente, a la que apunta con su certeza de verdad. Por ello podemos escuchar en palabras del escritor las siguientes sugerencias convincentes: "Ama las lejanías», «busca, busca»... Además de la sintaxis quebrada y del uso emocional del imperativo, toda la semántica de la entrega se pone al servicio de la construcción de la identidad humana genuina. El Hombre, con mayúsculas, aparece así descrito en sintagmas como los siguientes: «disuelto en lo pequeño», «buscaba hallar pleni- tud», «se perdía por lo más recóndito», «se desvivía, amaba»...

Es la poesía de José Luis Puerto, en definitiva, una poesía muy auténtica, al tiempo que enormemente esperanzada. Una poesía que, a pesar de su permanente registro de la injusticia, muestra los numerosos elementos con los que nos podemos salvar. Así lo manifiesta el escritor en el poema titulado «nos queda», donde indica que «nos queda el alma», el «vaso de cristal», el «amanecer», los «árboles», las «Sílabas limpias», las "palabras intactas», los «otros», la «mujer», el «viento», y todo ello dirigido a «que no fracase/ la melodía hermosa/ de la fraternidad». Es por ello un poemario que abre las ventanas de la vida y enseña a mirar y a sentir la belleza que nos rodea. No es fruto de una impostura intelectual, sino que anima al cambio vital necesario tras acercarse a un poemario. Consigue, de este modo, lo que a mi entender debería lograr cualquier libro, especialmente si este es de poesía, no dejar intacto al lector y que esté salga transformado de su lectura. Y, sin duda, tras leer Trazar la salvaguarda de José Luis Puerto uno vuelve de este viaje intelectual y vital siendo otro, tras haber tenido el privilegio de escuchar «ese rumor que purifica,/ el de los más humildes». 